\title{
MICROCOCCUS IN THE BLOOD
}

\author{
R. R. MARPLES AND JUdith F. RichaRdSON \\ Central Public Health Laboratory, Colindale Avenue, London NW9 5HT
}

BACTERAEMIA secondary to endocarditis as a complication of cardiac surgery occurs after some $0.9 \%$ of operations (Denton et al., 1957; Lord et al., 1961). The group of organisms most frequently implicated in infections on artificial valves are the coagulase-negative cocci (Braimbridge, 1969), usually Staphylococcus epidermidis (Speller and Mitchell, 1973). While some cases have been ascribed to micrococci (Keys and Hewitt, 1973; Rubin, Lyons and Murcia, 1978), there are few records of bacteraemia caused by organisms that would now be accepted as members of the genus Micrococcus. One such case was reported by Goodman et al. (1968) in which a 68-year-old male treated prophylactically with oxacillin developed endocarditis 8 weeks after operation due to an oxacillin-resistant organism identified as Micrococcus favus. We report the occurrence of Micrococcus strains in the blood in six patients.

\section{MATERIALS AND METHODS}

\section{Sources of strains}

The clinical details of the patients are listed in table I, which also shows the origins of the strains studied; the clinical and bacteriological features of case 6 have already been described by Old and McNeill (1979). Reference strains from the departmental collection (McKay-Ferguson, 1978) were as follows: $M$. lylae, strain CRF101 from Dr W. E. Kloos $=$ ATCC27566 $=$ CCM2693 (holotype); $M$. varians, strain $\mathrm{CRF} 222=\mathrm{NCTC} 7564=S$. lactis (holotype); $M$. luteus, strain CRF226 $=$ NCTC2665 $=M$. lysodeikticus (neotype); $M$. sedentarius, strain CRF96 from Dr W. E. Kloos=ATCC14392=CCM314 (holotype); S. aureus, strain CRF166 $=$ NCTC6571 $=$ Oxford staphylococcus.

\section{Biochemical and physiological tests}

The methods for the tests were those of Baird-Parker (1963) except where stated. Each strain was subcultured twice on nutrient agar at $30^{\circ} \mathrm{C}$; a tube of nutrient broth was inoculated from the second subculture and incubated overnight at $30^{\circ} \mathrm{C}$. Solid media were inoculated from this broth with a multiple-point inoculator and liquid media were seeded with 2-3 drops of the broth culture by pasteur pipette.

Mode of attack on glucose $(\mathrm{O} / \mathrm{F}$ test). The medium and method recommended by the International Committee on Bacterial Nomenclature (1965) were used. Acid production under anaerobic conditions was recorded as fermentative $(\mathrm{F})$, under aerobic conditions as oxidative $(\mathrm{O})$ and the absence of acid production in both tubes as no change $(-/-)$.

Acid production from "sugars". Plates were prepared from Baird-Parker's basal medium containing $0.5 \%(\mathrm{w} / \mathrm{v})$ of arabinose, fructose, lactose, maltose, mannitol, ribose, sucrose, trehalose, xylitol or xylose, with brom-cresol purple $0.004 \%(w / v)$ as indicator. After inoculation, the plates were incubated at $30^{\circ} \mathrm{C}$ and examined daily for 7 days. A change in the indicator from purple to yellow around the inoculum was recorded as ++ (strong) or + (weak).

Terminal $\mathrm{pH}$ and acetoin production. Glucose broth, $5 \mathrm{ml}$ in 28- $\mathrm{ml} \mathrm{screw-capped} \mathrm{bottles,} \mathrm{was}$ incubated for 14 days at $30^{\circ} \mathrm{C}$. The $p \mathrm{H}$ was measured with a Pye Dynacap $p \mathrm{H}$ meter and acetoin was detected by Barritt's method (Cowan, 1974).

Hydrolysis of arginine. Two methods were used. Arginine broth was incubated for 7 days 


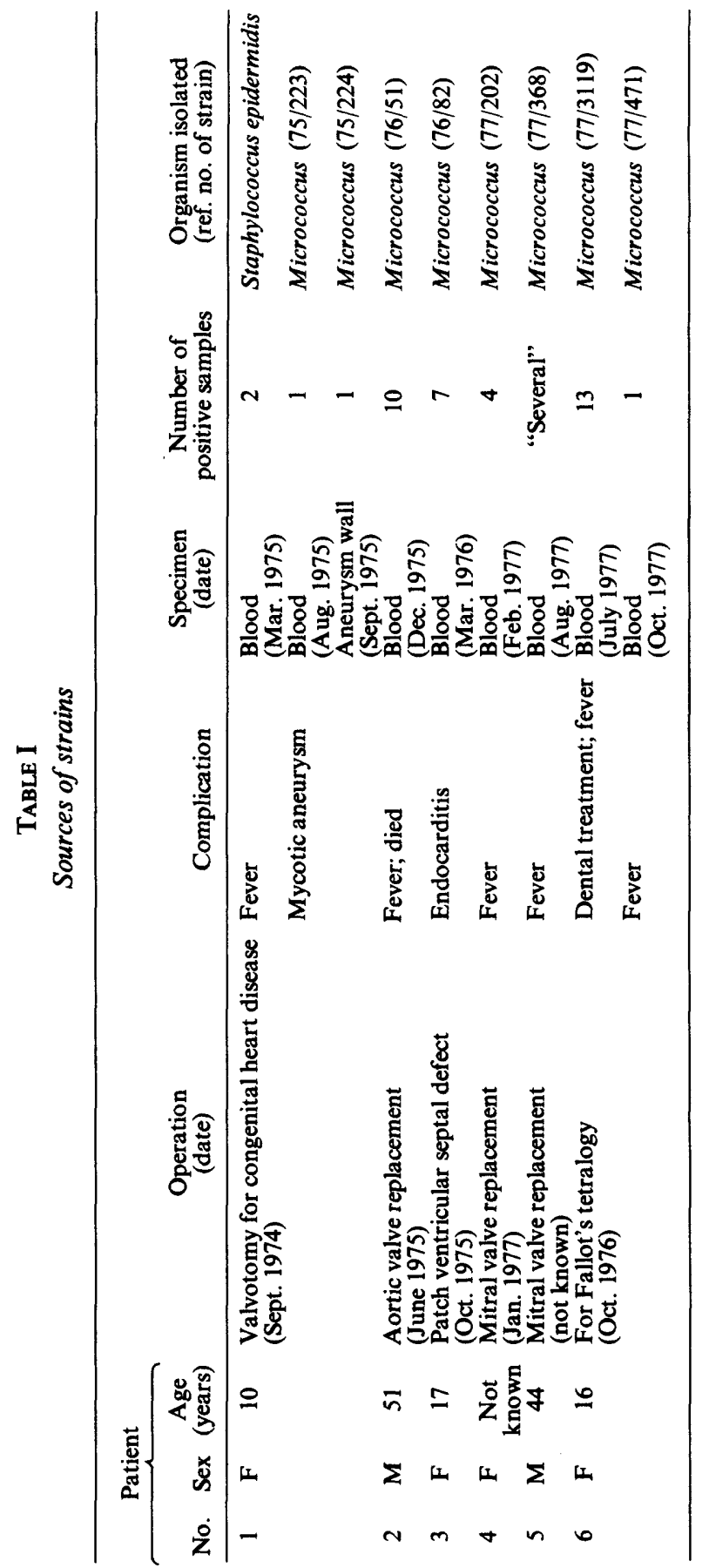


at $37^{\circ} \mathrm{C}$ and the presence of ammonia was detected by the development of a brown colour on the addition of Nessler's reagent. Møller's decarboxylase medium for arginine was incubated at $37^{\circ} \mathrm{C}$ for 4 days; a purple colour indicated hydrolysis (Cowan, 1974).

Growth on media containing $\mathrm{NaCl}$. Nutrient-agar plates containing $\mathrm{NaCl} \mathrm{5 \%}, 10 \%, 15 \%$ and $20 \%$ (w/v) were incubated for 7 days at $30^{\circ} \mathrm{C}$. Growth was scored on a scale of $0-4$ in comparison with the growth on nutrient agar.

DNAase. DNase Test Agar (Oxoid) was incubated for 5 days at $30^{\circ} \mathrm{C}$. Each plate was flooded with $1 \mathrm{~N} \mathrm{HCl}$ to precipitate residual DNA. Clearing around the inoculum indicated a positive result.

Gelatinase. Nutrient gelatin was incubated at $37^{\circ} \mathrm{C}$ for 2 weeks. Every second day the tubes were placed at $4^{\circ} \mathrm{C}$ for $30 \mathrm{~min}$. and the degree of liquefaction was recorded on a scale of $0-4$ where 4 indicated complete liquefaction.

Oxidase test. A drop of tetramethyl p-phenylene diamine dihydrochloride $1 \%(\mathrm{w} / \mathrm{v})$ in water was placed on the growth on nutrient agar. The rapid development of a blue colour was taken to indicate a positive result.

Phosphatase. Baird-Parker phosphatase agar was incubated for 5 days at $30^{\circ} \mathrm{C}$. Free phenolphthalein was detected by placing the plate over a filter paper moistened with aqueous ammonia $0.88 \mathrm{sp}$. gr. when a pink colour developed quickly.

$C A M P$ reaction. Sheep-blood agar was streaked diametrically with a culture of a $\beta$-lysinproducing strain of $S$. aureus. An inoculum from the broth culture of each organism was streaked up to the $S$. aureus inoculum and the plates were incubated at $37^{\circ} \mathrm{C}$ for $24 \mathrm{~h}$. A CAMP-factor-like substance was deemed to be present when a zone of complete haemolysis surrounded the test strain in the area of altered cells adjacent to the growth of $S$. aureus but no haemolysis was evident in the unaltered RBC.

Hydrolysis of Tweens. Tweens 20, 40,60 and 80 were incorporated into Sierra's medium (Cowan, 1974) and incubated for 7 days at $30^{\circ} \mathrm{C}$. The density of any precipitate was recorded on a scale of $0-4$ arbitrary units.

- Reduction of nitrate. Nitrate broth was incubated for 14 days at $30^{\circ} \mathrm{C}$. Nitrite was detected by the addition first of sulphanilic acid $0.8 \%(\mathrm{w} / \mathrm{v})$ in $5 \mathrm{~N}$ acetic acid and then of a saturated solution of Cleve's acid (1 napthylamine-7-sulphonic acid) in $5 \mathrm{~N}$ acetic acid. The rapid development of a red colour indicated reduction.

Minimum inhibitory concentration (MIC) of antibiotics and lysozyme. Plates of Diagnostic Sensitivity Test Agar (Oxoid CM261) were prepared containing doubling dilutions of: penicillin $\mathrm{G}, 0.032-8192$ units $/ \mathrm{ml}(0.02-5460 \mathrm{mg} /$ litre); methicillin $0.032-200 \mathrm{mg} /$ litre; streptomycin $0.032-4096 \mathrm{mg} /$ litre; erythromycin $0.032-200 \mathrm{mg} /$ litre; lincomycin $0.032-200 \mathrm{mg} /$ litre, and lysozyme $0 \cdot 19-1600 \mathrm{mg} / \mathrm{litre}$. A total of 25 strains were inoculated on each plate and the plates were incubated for $24 \mathrm{~h}$ at $37^{\circ} \mathrm{C}$. Growth was recorded on the scale: $++=$ good growth; $+=$ growth reduced; $\pm=$ growth only just perceptible, and $-=$ no growth.

DNA-base composition. One strain was examined in the National Collection of Type Cultures by equilibrium centrifugation in a neutral caesium chloride density gradient (Meselson, Stahl and Vinograd, 1957).

\section{RESULTS}

\section{Growth and microscopy}

The eight strains studied in detail grew well at $37^{\circ} \mathrm{C}$ to form small- to medium-sized, entire, matt, lenticular colonies of a grey to off-white colour. Microscopically, the cells were large gram-positive cocci with a tendency to packet formation. The cells were rather easily decolourised. $M$. sedentarius and $M$. lylae resembled the strains from patients in colonial characters. $M$. luteus and $M$. varians showed characteristic lemon-yellow pigmentation while $S$. aureus showed pastel orange pigmentation.

\section{Biochemical results}

The eight study strains behaved similarly in most tests (table II). None produced acid in the 


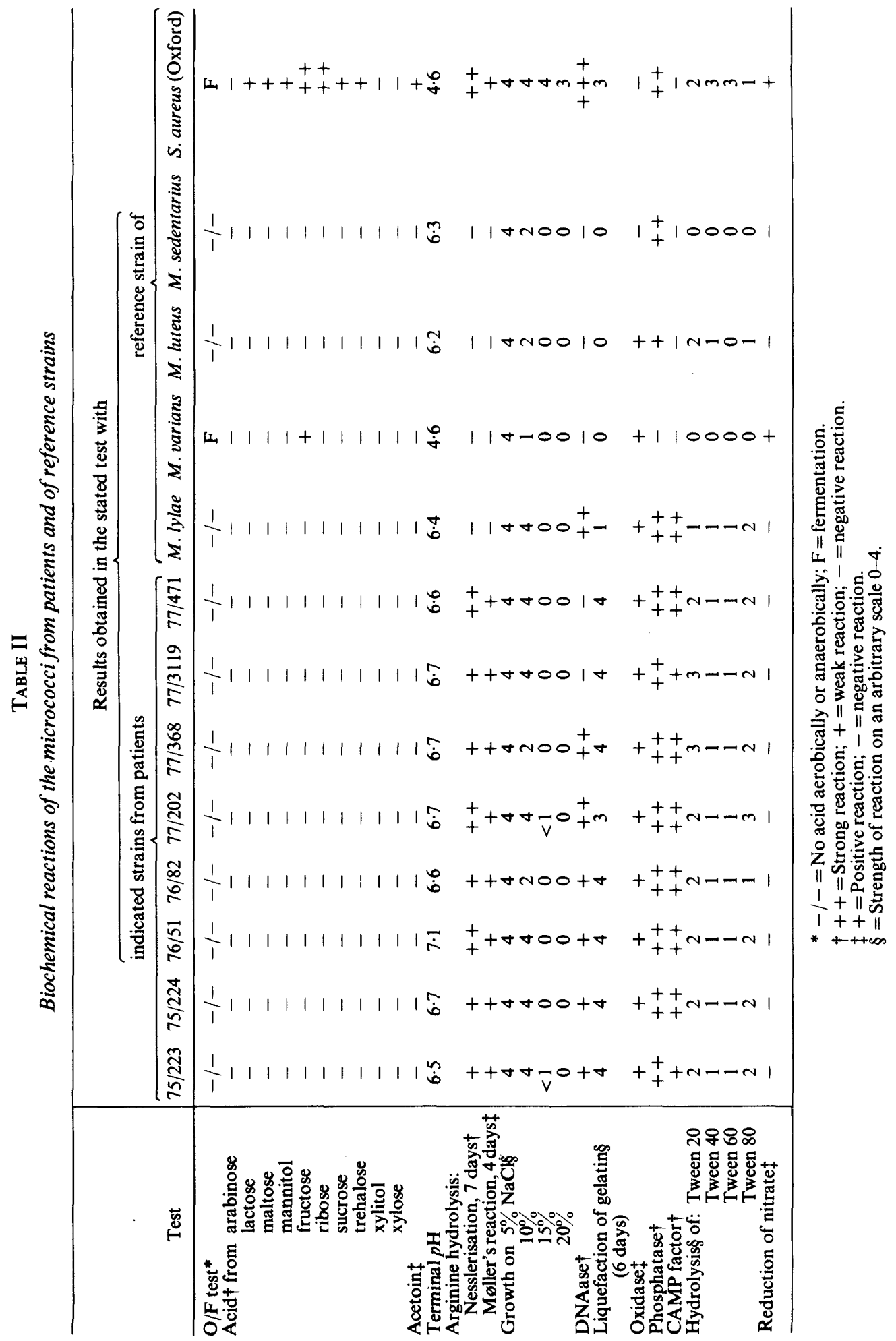




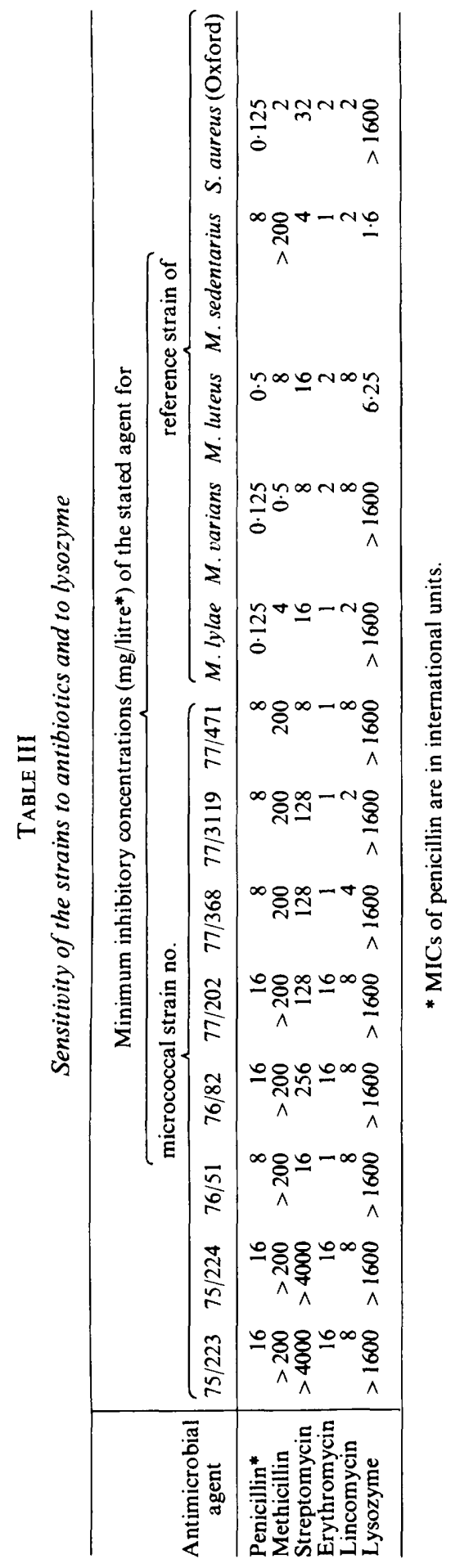


$\mathrm{O} / \mathrm{F}$ test nor from any of the ten 'sugars'. Acetoin was not produced, the $p \mathrm{H}$ in glucose broth was more than 6.5 and nitrate was not reduced. All strains produced ammonia in arginine broth, liquefied gelatin and gave positive tests for oxidase, phosphatase and CAMP factor. Tweens 20 and 80 were split. Variable results were recorded for DNAase, growth on salt agar and, to an extent, in the strength of Tween-splitting activity.

Of the reference strains, $M$. lylae differed from the patients' strains only in failing to hydrolyse arginine and in causing less liquefaction of gelatin. $M$. varians differed from the patients' strains in producing acid from glucose and fructose, in reducing nitrate, in failing to hydrolyse arginine, gelatin and Tweens and in giving negative results in tests for phosphatase and CAMP factor. M. luteus could be distinguished from the strains from patients by failing to hydrolyse arginine or gelatin or to produce a CAMP-factor-like substance, while $M$. sedentarius differed from the patients' strains in giving negative results in tests for hydrolysis of arginine, gelatin and Tweens, for CAMP factor and oxidase. The reactions of the named strains were similar to those described (Kloos, Tornabene and Schleifer, 1974) except for the fermentative attack on glucose found for $M$. varians.

\section{Susceptibility to antibiotics and lysozyme}

Table III lists the minimum inhibitory concentrations of antibiotics for the strains. The strains from patients were resistant to moderate levels of penicillin, and to high levels of methicillin and lysozyme; resistance to streptomycin and erythromycin was variable. $M$. sedentarius was resistant to penicillin and methicillin only, while $M$. lylae and $M$. varians were resistant only to lysozyme. $M$. luteus was susceptible to all the agents tested.

The values found for the MIC of erythromycin and streptomycin for $M$. lylae were higher than those reported by Kloos et al., (1974) for the same strain.

The base-composition of the DNA was assessed for strain $76 / 82$ as $\mathrm{G}+\mathrm{C}=71 \cdot 8 \%$.

\section{Discussion}

There seems little doubt that the strains were multiplying within the body in each patient. Similar organisms were repeatedly isolated from the blood or from blood and surgical specimens, and the patients had all been subjected to extensive cardiac surgery, often including the insertion of prosthetic material.

Although the six patients were in hospital at different times over a period of years, and were in five hospitals, the strains were remarkably similar in their properties. The strains were identified as Micrococcus on the basis of morphological and colonial appearance, lack of acid production from "sugars", lack of acetoin production but positive oxidase reaction. The one strain examined for guanine-cytosine content showed this to be in the Micrococcus range.

Some characters were unusual for Micrococcus. The ability to produce ammonia from arginine has been proposed as a means of differentiating Staphylococcus from Micrococcus (Peny and Buissière, 1970), but the eight strains from the six patients were positive in arginine broth and when tested by Møller's method. The reference strains of Micrococcus gave negative reactions.

The study strains from patients could be distinguished from $M$. kristinae because the latter produces acid from glucose and by colonial appearance from $M$. nishinomiyaensis, which has small, bright orange, slow-growing colonies (Kloos et al. 1974). They differed from $M$. luteus, $M$. varians and $M$. sedentarius in several tests and from $M$. lylae in arginine and gelatin hydrolysis only. Antibiotic-susceptibility tests showed that the strains from patients were all resistant to methicillin with MIC values of $200 \mathrm{mg} /$ litre or greater; this was true only for $M$. sedentarius among the reference strains. Kloos et al., (1974) state that methicillin resistance appears to be species specific for $M$. sedentarius. The strains from patients differed slightly from $M$. lylae and to a greater degree from the other reference strains in biochemical and in antibiotic-resistance characters. Whether the differences are of taxonomic value or are selected by growing in the heart is uncertain.

The frequency of septicaemia due to species of Micrococcus is difficult to ascertain. Over the 
3-year period during which the six patients studied here presented, this laboratory received 221 strains of coagulase-negative cocci isolated from the blood of 81 patients. The majority (171 isolates from 66 patients) were identified as Staphylococcus epidermidis, 12 isolates from six patients were identified as $S$. saprophyticus, and Micrococcus was found in only eight patients, from two of whom there were single isolations, probably contaminants. This finding, however, probably overestimates the general frequency of micrococcal septicaemia. In a study of infections in a cardiac-surgery unit, no blood cultures obtained after 200 operations in which a prosthetic valve was implanted were positive for Micrococcus (Marples et al., 1978). The case reported by Goodman et al. (1968) shows close resemblances to those reported here. A recent report implicated Micrococcus mucilaginosus incertae sedis in a patient with chronic valvular disease after cardiac catheterisation (Rubin et al., 1978). The organism was catalase negative, grew on solid media only in an atmosphere with added $\mathrm{CO}_{2}$ and was sensitive to the antibiotics tested. A source in the oral cavity was suspected.

\section{SUMMARY}

Eight isolates of micrococci from the bloodstream of six patients obtained under circumstances suggesting a pathogenic role were studied in detail. The organisms were remarkably uniform in cultural, biochemical and antibiotic-susceptibility characters. All strains showed high resistance to methicillin and hydrolysed arginine. The characters found did not correspond with those of any hitherto described species, but were closest to Micrococcus lylae.

We thank Mrs J. A. Crees-Morris for technical assistance and Dr L. R. Hill and the staff of the National Collection of Type Cultures for determination of the DNA-base composition.

\section{REFERENCES}

BAIRD-PARKer, A. C. 1963. A classification of micrococci and staphylococci based on physiological and biochemical tests. J. gen. Microbiol., 30, 409.

BRAIMBRIDGE, M. V. 1969. Cardiac surgery and bacterial endocarditis. Lancet, 1, 1307.

Cowan, S. T. 1974. Cowan and Steel's Manual for the identification of medical bacteria, 2nd ed. Cambridge University Press: Cambridge.

Denton, C., Pappas, E. G., Uricchio, J. F., Goldberg, H. and Likoff, W. 1957. Bacterial endocarditis following cardiac surgery. Circulation., 15, 525.

Goodman, J. S., Schaffner, W., Collins, H. A., Battersby, E. J. and Koenig, M. G. 1968. Infection after cardiovascular surgery. New Engl. J. Med. 278, 117.

InTERNATIONAL COMMITTEE ON BACTERIAL NOMENClature. 1965. Subcommittee on Taxonomy of Staphylococci and Micrococci; recommendations. Int. J. syst. Bact., 15, 109.

KeYs, T. F. AND HewITT, W. L. 1973. Endocarditis due to micrococci and Staphylococcus epidermidis. Archs intern. Med., 132, 216.

KLOOS, W. E., TORNABENE, T. G. AND SCHLEIFER, K. H. 1974. Isolation and characterisation of micrococci from human skin including two new species: Micrococcus lylae and Micrococcus kristinae. Int. J. syst. Bact., 24, 79.

LORD, J. W., Imperato, A. M., HACKel, A. AND Doyle, E. F. 1961. Endocarditis complicating open-heart surgery. Circulation, 23, 489.

MCKay-Ferguson, E. 1978. Organic acids as substrates in microbiology. MD Thesis. University of London.

Marples, R. R., Hone, R., Notley, C. M., Richardson, J. F. and Crees-Morris, J. A. 1978. Investigation of coagulase-negative staphylococci from infections in surgical patients. Zentbl. Bakt. ParasitKde, I. Abt. Orig., 241, 140.

Meselson, M., STAHL, F. W. AND VINOGRAD, J. 1957. Equilibrium sedimentation of macromolecules in density gradients. Proc. natn. Acad. Sci. U.S.A., 43, 581.

Old, D. C. AND MCNEILL, G. P. 1979. Endocarditis due to Micrococcus sedentarius incertae sedis. J. clin. Path., 32, 951. 
PENY, J. AND BuIssière, J. 1970. Microméthode d'identification des bactéries. II. Identification du genre Staphylococcus. Annls. Inst. Pasteur, Paris, 118, 10.

Rubin, S. J., Lyons, R. W. AND MurCia, A. J. 1978. Endocarditis associated with cardiac catheterization due to a gram-positive coccus designated Micrococcus mucilaginosus incertae sedis. J. clin. Microbiol., 7, 546.

Speller, D. C. E. AND Mitchell, R. G. 1973. Coagulase-negative staphylococci causing endocarditis after cardiac surgery. J. clin. Path., 26, 517. 